\title{
Diagnóstico Pré-Natal de Trombose da Veia Cava Inferior
}

\author{
Prenatal Diagnosis of Inferior Vena Cava Thrombosis
}

Tânia ASCENSÃO $\mathbb{1}^{1}$, Nuno PEREIRA², Miguel BRANCO'1

Acta Med Port 2022 Jun;35(6):492-493 - https://doi.org/10.20344/amp.16201

Palavras-chave: Doenças Fetais/diagnóstico por imagem; Ecografia Prenatal; Veia Cava Inferior/anomalias congénitas; Veia Cava Inferior/diagnóstico por imagem; Trombose/diagnóstico por imagem

Keywords: Fetal Diseases/diagnostic imaging; Thrombosis/diagnostic imaging; Ultrasonography, Prenatal; Vena Cava, Inferior/abnormalities; Vena Cava, Inferior/diagnostic imaging

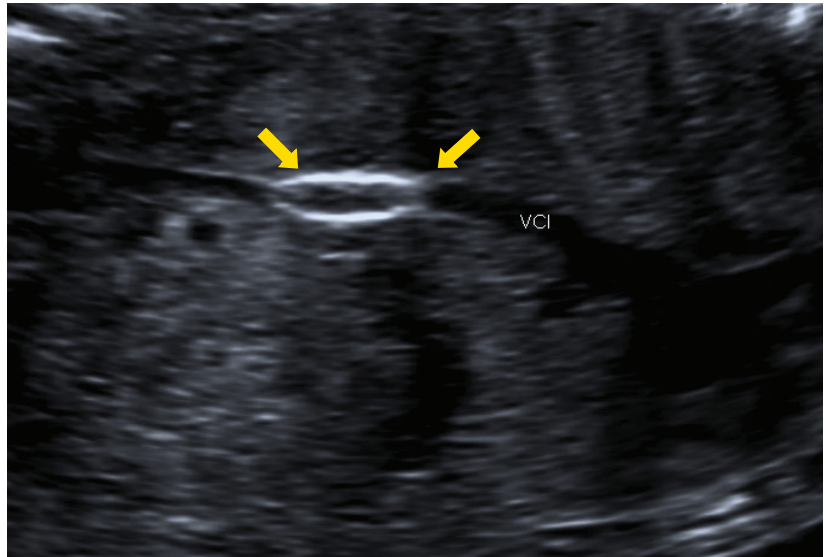

Figura 1 - Trombo calcificado no trajecto retrohepático da VCI

Gestante de 37 anos, saudável, realizou ecografia morfológica que mostrou trombo calcificado de $10 \times 3 \mathrm{~mm}$ no trajecto retrohepático da veia cava inferior ( $\mathrm{VCl}$ ) (Fig. 1) com fluxo intermitente (Fig. 2) e circulação colateral pela veia ázigos com vascularização renal normal. $\mathrm{O}$ estudo das trombofilias do casal foi negativo, tendo-se ainda excluído patologia hipertensiva, diabetes e infecção materna (incluindo a citomegalovírus), com vigilância posterior revelando estabilidade do trombo. O parto realizou-se às 38 semanas: recém-nascido masculino, 3715 gramas, índice de Apgar 9/10/10. O Doppler abdominal neonatal revelou $\mathrm{VCl}$ com imagem intraluminal calcificada bem como circulação colateral envolvendo o sistema ázigos, apresentando estudo das trombofilias normal. Actualmente, e com dois anos, a criança encontra-se assintomática, com indicação para profilaxia em caso de risco trombótico acrescido, como em contextos de imobilização prolongada. O diagnóstico pré-natal de trombose da $\mathrm{VCl}$ é raro, podendo ter etiologia materna, fetal ou idiopática. ${ }^{1-3} \mathrm{~A}$ trombose concomitante da veia renal é comum, mas quando representa um achado isolado tem geralmente prognóstico favorável. ${ }^{2,3}$ É frequente o desenvolvimento de uma rede vascular colateral, asso-

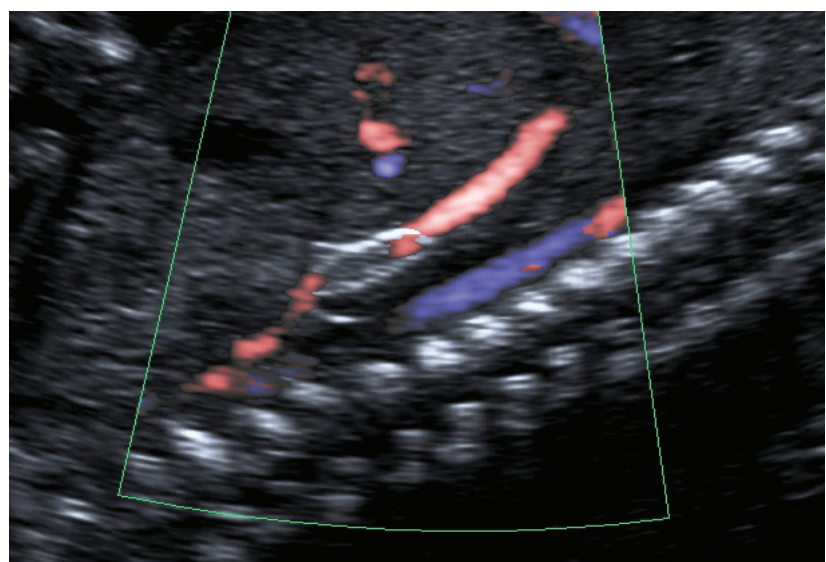

Figura 2 - Trajecto retrohepático da $\mathrm{VCl}$ revelando trombo e fluxo intermitente

ciado a um bom processo adaptativo e desfecho neonatal. ${ }^{2}$

\section{CONTRIBUTO DOS AUTORES}

TA: Escolha das imagens. Elaboração do texto. Pesquisa bibliográfica.

NP, MB: Escolha das imagens. Pesquisa bibliográfica. Correcção do texto.

\section{PROTECÇÃO DE PESSOAS E ANIMAIS}

Os autores declaram que os procedimentos seguidos estavam de acordo com os regulamentos estabelecidos pelos responsáveis da Comissão de Investigação Clínica e Ética e de acordo com a Declaração de Helsínquia da Associação Médica Mundial atualizada em 2013.

\section{CONFIDENCIALIDADE DOS DADOS}

Os autores declaram ter seguido os protocolos do seu centro de trabalho acerca da publicação de dados.

\section{CONSENTIMENTO INFORMADO}

Obtido.

\footnotetext{
1. Serviço de Ginecologia e Obstetrícia. Centro Hospitalar e Universitário de Coimbra. Coimbra. Portugal.

2. Serviço de Obstetrícia. Centro Hospitalar Tondela Viseu. Viseu. Portugal.

$\triangle$ Autor correspondente: Tânia Ascensão. tania_ascensao@hotmail.com

Recebido/Received: 14/03/2021 - Aceite/Accepted: 13/05/2021 - Publicado Online/Published Online: 16/06/2021 - Publicado/Published: 01/06/2022

Copyright @ Ordem dos Médicos 2022
} 


\section{CONFLITOS DE INTERESSE}

Os autores declaram não ter quaisquer conflitos de interesse relativamente ao presente artigo.

\section{REFERÊNCIAS}

1. Smorgick N, Herman A, Wiener Y, Halperin R, Sherman D. Prenatal thrombosis of the inferior vena cava and the renal veins. Prenat Diagn. 2007;27:603-7.

2. Boussicault G, Sentilhes L, Cipierre C, Lépinard C, Bouderlique C. Successful outcome of and idiopathic thrombosis of the fetal inferior

\section{FONTES DE FINANCIAMENTO}

Sem fontes externas de financiamento para a realização deste artigo.

vena cava. Ultrasound Obstet Gynecol. 2009;33:611-2.

3. Moreno A, Díaz J, Frontela C, Viñas O, López M. Trombosis fetal extensa de vena cava inferior y vena renal derecha. Prog Obstet Ginecol. 2014;57:172-5. 